\title{
Thermal exchange optimization based control of a doubly fed induction generator in wind energy conversion systems
}

\author{
Mohammed Mazen Alhato ${ }^{1}$, Soufiene Bouallègue ${ }^{2}$ \\ ${ }^{1,2}$ Research Laboratory in Automatic Control (LARA), National Engineering School of Tunis (ENIT), Tunisia \\ ${ }^{2}$ High Institute of Industrial Systems of Gabès, Tunisia
}

\begin{tabular}{lll}
\hline \hline Article Info & ABSTRACT \\
\cline { 2 - 3 } Article history: & $\begin{array}{l}\text { This paper introduces a recent design method to acquire the best gains of } \\
\text { proportional-integral (PI) regulators for a doubly-fed induction generator } \\
\text { Received Aug 4, } 2019\end{array}$ & $\begin{array}{l}\text { (DFIG) in wind energy based on a thermal exchange optimization (TEO) } \\
\text { algorithm. Since the gains of PI regulators are generally tuned by traditional } \\
\text { and tedious trials-errors based method, their adjusting for such a wind energy } \\
\text { converter is built as a constrained nonlinear optimization issue. Inspired by }\end{array}$ \\
Accepted Jun 1, 2020 & $\begin{array}{l}\text { Newton's law of cooling, the TEO method is successfully adopted to process } \\
\text { such a control problem under time-domain performances and operational }\end{array}$ \\
Keywords: & $\begin{array}{l}\text { constraints in order to catch more quantity from the available power. } \\
\text { In order to assess the power of the proposed TEO method, a comparative } \\
\text { study between the TEO algorithm and homologues ones is performed. }\end{array}$ \\
Advanced metaheuristics & $\begin{array}{l}\text { In addition, a statistical measurement via Friedman and Bonferroni-Dunn's } \\
\text { tests indicates that the TEO method presents high meaningful results in } \\
\text { Doubly fed induction generator } \\
\text { Energy conversion }\end{array}$ & $\begin{array}{l}\text { comparison to the other reported metaheuristic methods. } \\
\text { PI control setting }\end{array}$ Thermal exchange optimization
\end{tabular}

Copyright $\odot 2020$ Institute of Advanced Engineering and Science. All rights reserved.

\section{Corresponding Author:}

Mohammed Mazen ALhato,

Research Laboratory in Automatic Control (LARA),

National Engineering School of Tunis (ENIT), Le Belvédère, Tunis 1002, Tunisia.

Email: mohammed.alhato@enit.utm.tn

\section{INTRODUCTION}

Recently, wind power represents a promising resolution for the power electrical request. Recently and as on global wind statistics of the world wind energy association (WWEA) in 2018, the total wind energy capacities attained in the wind market $596.556 \mathrm{GW}$ at the end of 2018. Various wind energy installations are manufactured. The most popular one is the DFIGs joined with wind turbines (WTs). A DFIG is a wound rotor generator. The rotor windings are linked to the grid via a power converter that is consist of rotor side converter (RSC) and grid side converter (GSC) parts. The stator windings are straightly joined to the network [1-3].

Traditionally, the DFIG system is regulated by employing the vector control (VC) method. This control approach guarantees a decoupled control of the power components exchanging between the grid and the generator. The control of stator active and reactive powers are achieved through adopting PI regulators [3-5]. The main disadvantage for this kind of control is that the effectiveness of the DFIG robustly relies on an adequate setting of the PI controller components. Commonly, these active control gains are ordinarily picked up by trials-errors based methods. The setting procedure can be time-consuming and difficult. With a view to outperform this problem, introducing a methodical strategy to acquire the fine gains of PI regulators is an interesting work. The metaheuristics-based hard optimization notion seems a favourable resolution [6-14].

Many algorithms were developed to define the gains of PI regulators. In [10], a gravitational search algorithm (GSA) was applied to determine the PI controller for the stator power components. 
Moreover, a fair comparison between the proposed GSA and other homologues ones are adopted, which the results indicated the superior of the GSA. In [12], a genetic algorithm (GA) was applied to define the gains of the PI regulators at the rotor side. The particle swarm optimization (PSO) approach was adopted to attain the optimized PI parameters for indirect control of stator power components. Integral absolute error (IAE) and integral square error (ISE) indices were chosen as fitness functions [13]. Although, the PI controllers tuned by previous methods are better than the ones tunned traditionally. The premature convergence in local minima degrades the performances of the controlled system.

Moreover, all of these studies were applied to the PI controllers at the RSC with any discussion about the PI ones at the GSC circuit. To overcome the disadvantages of the aforementioned methods, the contribution of this work is applying a thermal exchange optimization (TEO) method to obtain the parameters of all external-loop PI regulators in the VC scheme of DFIG systems at both RSC and GSC parts. Especially, this paper addresses with the PI regulators adjusting for the stator reactive power and the speed control loops at the rotor side. It also discusses the PI controller optimization-based DC-link voltage loop. The TEO technique is inspired by physical concepts [15]. The TEO algorithm prevents effectively-being enclosed in local minima in the first iterations and has developed the exploration and exploitation mechanisms to solve such a problem.

This work is arranged as: The mathematical representation of the DFIG-based WT is derived in Section 2. The VC scheme of the DFIG is described in Section 3. Section 4 is suited to the formulation of the external-loops PI regulators' setting issue introduced as a constrained optimization issue to be processed by the introduced TEO method. In Section 5, the TEO method is detailed. Section 6 presents the implementation of the introduced TEO-adjusted PI controllers strategy. Concluding notes are presented in Section 7.

\section{MODELLING OF THE DFIG \\ 2.2. Modelling of the wind turbine}

The function of the WT is capturing the available energy from the wind. The captured power $P_{m}$ is given as [3]:

$$
P_{m}=\frac{1}{2} \rho C_{p}(\lambda, \beta) \pi R^{2} V_{w}^{3}
$$

where $\rho$ the air density, $R$ the turbine radius, $V_{w}$ the wind speed, $C_{p}$ the power conversion efficiency, $\lambda$ the tip-speed ratioa and $\beta$ the blade pitch angle.

\subsection{Modelling of the DFIG}

The mathematical representation of the investigated DFIG can be defined as [3, 4]:

$$
\left\{\begin{array} { l } 
{ V _ { d s } = R _ { s } i _ { d s } + \frac { d \varphi _ { d s } } { d t } - \omega _ { s } \varphi _ { q s } } \\
{ V _ { q s } = R _ { s } i _ { q s } + \frac { d \varphi _ { q s } } { d t } + \omega _ { s } \varphi _ { d s } } \\
{ V _ { d r } = R _ { r } i _ { d r } + \frac { d \varphi _ { d r } } { d t } - ( \omega _ { s } - \omega _ { m } ) \varphi _ { q r } } \\
{ V _ { q r } = R _ { r } i _ { q r } + \frac { d \varphi _ { q r } } { d t } + ( \omega _ { s } - \omega _ { m } ) \varphi _ { d r } }
\end{array} , \text { where } \left\{\begin{array}{l}
\varphi_{d s}=L_{s} i_{d s}+L_{m} i_{d r} \text { and } \varphi_{q s}=L_{s} i_{q s}+L_{m} i_{q r}+L_{m} i_{d s} \text { and } \varphi_{q r}=L_{r} i_{q r}+L_{m} i_{q s}
\end{array}\right.\right.
$$

where $V_{s}$ and $i_{s}$ are the stator voltage and current, $V_{r}$ and $i_{r}$ are the rotor voltage and current, $\varphi_{s}$ and $\varphi_{r}$ are the stator and rotor flux linkages, $R_{s}$ and $R_{r}$ are the stator and rotor resistances, $\omega_{s}$ and $\omega_{m}$ are the stator and rotor angular frequencies, where $L_{s}, L_{r}$ and $L_{m}$ are the stator, rotor and magnetizing inductances, respectively. 


\section{VECTOR CONTROL OF THE DFIG}

The traditional DFIG control system is separated into the RSC and GSC control parts [12-14]. The conventional control schemes composed of two cascaded control levels. The internal PI levels are employed to adjust the current parts on both sides. Furthermore, the external PI ones in the rotor side are used to regulate the reactive power and speed control loops. The external PI layer in the grid side is investigated to regulate the DC-link voltage. In this research paper, the external PI loops are adjusted based on the introduced TEO algorithm.

\subsection{Control of the RSC}

The stator active and reactive powers are expressed by:

$$
\left\{\begin{array}{l}
P_{s}=\frac{3}{2}\left(V_{d s} i_{d s}+V_{q s} i_{q s}\right)=-\frac{3}{2} \frac{L_{m}}{L_{s}} V_{d s} i_{d r} \\
Q_{s}=\frac{3}{2}\left(V_{q s} i_{d s}-V_{d s} i_{q s}\right)=-\frac{3}{2} \frac{1}{L_{s}} V_{d s}\left(\varphi_{s}-L_{m} i_{q r}\right)
\end{array}\right.
$$

It is clear in (3) that the direct rotor current controls stator active power while the quadrature rotor current controls the stator reactive power [16-18]. The rotor voltages in the d-q frame are defined by:

$$
\left\{\begin{array}{l}
V_{d r}=R_{r} i_{d r}+\sigma L_{r} \frac{d i_{d r}}{d t}-\left(\omega_{s}-\omega_{m}\right)\left(\sigma L_{r} i_{q r}+\frac{L_{m}}{L_{s}} \varphi_{q s}\right) \\
V_{q r}=R_{r} i_{q r}+\sigma L_{r} \frac{d i_{q r}}{d t}+\left(\omega_{s}-\omega_{m}\right) \sigma L_{r} i_{d r} \quad, \text { where } \sigma=\left(L_{r}-L_{m}^{2} / L_{s}\right)
\end{array}\right.
$$

The PI controller gains for the rotor current loop by using the pole-assignment method are found [17]:

$$
\left\{\begin{array}{l}
K_{p i_{r}}=2 \xi \omega_{n} \sigma L_{r}-R_{r} \\
K_{i i_{r}}=\sigma L_{r} \omega_{n}^{2}
\end{array}\right.
$$

where $\xi$ the damping coefficient and $\omega_{n}$ the natural frequency.

\subsection{Control of the GSC}

The main target for controlling the grid side converter is to make the DC-link voltage stable [16-19]. In the $\mathrm{d}-\mathrm{q}$ reference framework, the $\mathrm{d}$-axis is ranged with the grid vector voltage. As a result, the d-axis grid voltage $e_{d g}$ is equal to its magnitude. Hence, the grid power terms are defined as in (6):

$$
\left\{\begin{array}{l}
P_{g}=\frac{3}{2} e_{d g} i_{d g} \\
Q_{g}=-\frac{3}{2} e_{q g} i_{q g}
\end{array}\right.
$$

It is clear from (6) that the active power $P_{g}$, and consequently the DC-link voltage is regulated through the direct current $i_{d g}$. While the quadrature current $i_{q g}$ is employed to control the reactive power $Q_{g}$ [16-19].

\section{PI CONTROLLERS TUNING PROBLEM FORMULATION}

The appropriate values of PI parameters are chosen by trials-errors based methods. These methods are non-methodical and time-consuming. Therefore, the idea of formulating gains adjusting as an optimization issue is a favourable resolution for the DFIG control framework. This kind of control problems 
can be resolved by using metaheuristics algorithms. For our case, three optimization-tuned PI regulators for the DC-link voltage, reactive power and speed control loops are considered. The proposed TEO algorithm will tune these PI controllers. The considered variables of such an optimization issue are the PI gains and are denoted as:

$$
\boldsymbol{x}=\left[K_{p d c}, K_{i d c}, K_{p \mathrm{var}}, K_{i \mathrm{var}}, K_{p s p e}, K_{i s p e}\right]^{T} \in \mathbb{R}_{+}^{6}
$$

where $K_{p d c}$ and $K_{i d c}$ are the proportional and integral factors of the PI regulator for the DC-link regulation, $K_{p \text { var }}$ and $K_{i \text { var }}$ are the ones for the reactive power loop, $K_{p s p e}$ and $K_{i s p e}$ and denote the control gains for the speed control dynamics. These considered variables are adopted to reduce defined performance criteria under operational constraints like the maximum overshoot $\delta^{\max }(\%)$, steady-state error $E_{s s}$, and rise and/or settling times $t_{r}(\mathrm{sec})$ and $t_{s}(\mathrm{sec})$ of the closed-loop system step responses $[6,7]$.

The optimization-based adjusting issue is eventually described as in (8):

$$
\left\{\begin{array}{l}
\operatorname{minimize} f_{i}(\boldsymbol{x}) \\
\boldsymbol{x}=\left[K_{p d c}, K_{i d c}, K_{p \mathrm{var}}, K_{i \mathrm{var}}, K_{p s p e}, K_{i s p e}\right]^{T} \in \mathbb{S} \subseteq \mathbb{R}_{+}^{6} \\
\text { subject to : } \\
g_{1}(\boldsymbol{x})=\delta_{d c}-\delta_{d c}^{\max } \leq 0 \\
g_{2}(\boldsymbol{x})=\delta_{\mathrm{var}}-\delta_{\mathrm{var}}^{\max } \leq 0 \\
g_{3}(\boldsymbol{x})=\delta_{\text {speed }}-\delta_{\text {speed }}^{\max } \leq 0
\end{array}\right.
$$

where $f_{i}: \mathbb{R}_{+}^{6} \rightarrow \mathbb{R}, i \in\{1,2,3\}$ are the fitness functions specified as the well-known IAE and ISE performance criteria,i.e. $f_{I A E, i}(\boldsymbol{x})=\int_{0}^{\infty}\left|e_{i}(\boldsymbol{x}, t)\right| d t$ and $f_{I S E, i}(\boldsymbol{x})=\int_{0}^{\infty} e_{i}(\boldsymbol{x}, t)^{2} d t$, respectively, $e_{i}($.$) indicate$ the tracking errors between the plant output and the relative reference values, and, $\mathbb{S}=\left\{\boldsymbol{x} \in \mathbb{R}_{+}^{6}, \boldsymbol{x}_{\text {low }} \leq \boldsymbol{x} \leq \boldsymbol{x}_{u p}\right\}$ is the bounded search space and $g_{j}: \mathbb{R}_{+}^{6} \rightarrow \mathbb{R}, j \in\{1,2,3\}$ are the problem inequality limitations. The nations $\delta_{d c}, \delta_{\text {var }}$ and $\delta_{\text {speed }}$ are the overshoots of the DC-link voltage, reactive power and rotor speed dynamics, respectively.

\section{THERMAL EXCHANGE OPTIMIZATION ALGORITHM}

The TEO method is a new metaheuristic created by Newton's law of the cooling [15]. In this advanced metaheuristic, each agent is considered as a cooling object and by joining another agent as a surrounding fluid, heat transfer and thermal exchanging occur between them. The new temperature of each agent is defined as its new position in the search space. In a $d$-dimensional search space, each object at the iteration time $\boldsymbol{k}$ is given by its temperature $\boldsymbol{T}_{i}^{k}$. In order to upgrade the efficiency of the optimization, the TEO approach employs a Thermal Memory $(T M)$ to save a number of historically best $\boldsymbol{T}$ vectors and their related cost functions. Therefore, the solution vectors that are stored in the $T M$ are supplemented to the population and the equal numbers of current worst objects are removed. The $N_{\text {pop }}$ arranged objects are evenly separated into two collections of environment and cooling objects. The environment objects are $T_{1}^{k}, T_{2}^{k}, \ldots, T_{\frac{N_{p o p}}{2}}^{k}$ while the cooling ones are $T_{\frac{N_{p o p}}{2}+1}^{k}, T_{\frac{N_{p o p}}{2}+2}^{k}, \ldots, T_{N_{p o p}}^{k}$.

By inspiring, the feature that states that the object has lower $\alpha$ can alternate the temperature lightly. The TEO method introduced an analogous formulation to estimate the value of $\alpha$ for each object as in (9):

$$
\alpha=\frac{\text { Cost (object) }}{\text { Cost (worst object) }}
$$


In order to intensify the convergence rate of the TEO method, (10) has been introduced to prevent the restricting in local optima, which is adopted to upgrade the environmental temperature as in (10):

$$
T_{e n v, i}^{k+1}=\left(1-\mathcal{U}\{0,1\}\left(c_{1}+c_{2}(1-t)\right)\right) T_{e n v, i}^{k}
$$

where $c_{1}$ and $c_{2}$ are the controlling variables and can be chosen as 0 or $1, \mathcal{U}\{0,1\}$ is a uniformly random variable. Over the course of iterations, the value of $t=\frac{k}{k_{\max }}$ rises leading to upgrading the exploration technique. The new temperatures for both types of agent are changed:

$$
T_{i}^{k+1}=T_{e n v, i}^{k}+\left(T_{i}^{k}-T_{e n v, i}^{k}\right) e^{(-\alpha t)}
$$

In the TEO method, other scale is adopted to increase exploration efficiency. The input pro within 0,1 is presented and defines whether a component of each cooling object must be modified or not. For each object, the control parameter pro is matched with $\operatorname{Rand}(i)\left(i=1,2, \ldots, N_{\text {pop }}\right)$ which is a random number regularly distributed between 0 and 1 . If $\operatorname{Rand}(i)<$ pro, one dimension of the $i^{\text {th }}$ object is selected randomly and its value is reproduced as in (12) [15, 20]:

$$
T_{(i, j)}=T_{j, \min }+\mathcal{U}(0,1) \times\left(T_{j, \max }-T_{j, \min }\right)
$$

where $T_{(i, j)}$ is the $j^{\text {th }}$ component of the $i^{\text {th }}$ object, $T_{j, \max }$ and $T_{j, \min }$ are the upper and lower bounds.

\section{SIMULATION RESULTS AND ANALYSIS}

\subsection{Execution of the TEO algorithm}

In order to investigate the executions of the adjusted PI regulators, the methods GA, PSO, HSA and WCA are adopted for the rapprochement objectives. The population size adjusted to 50 and the maximum number of iterations adjusted to 100, were adopted to be equal. Table 1 lists the statistical outputs generated by the introduced methods for the IAE and ISE indices. It can be obviously noticed from Table 1 that the most performances indicators of TEO algorithm are better than those of the other methods. Moreover, Figure 1 shows that the TEO algorithm results outperform the other methods in terms of convergence fitness and the solution quality. In terms of computation time, the HSA method was superior to all other reported algorithms including the TEO one. However, the TEO metaheuristic offers smaller cost function values compared to the HSA technique. In order to assess the capability of the introduced TEO method in detecting the optimal solution, two scenarios are considered, i.e. the natural situation and the dip voltage of the grid.

In the first scenario, Figure 2 shows the closed-loop system responses against various levels for the reactive power and the DC-link voltage. From these results, it is noted that the TEO algorithm maintains the reactive power and the DC-link voltage better than other methods. In the second scenario, $25 \%$ of the voltage decay from the normal value is investigated. Figure 3 illustrates the closed-loop system response acquired against the voltage dip from which, it can justify that the TEO algorithm-based approach can maintain the disturbed system more quickly with less value of overshoot for the considered ISE performance index. Furthermore, Figure 4 a shows a comparison of the reactive power responses for the TEO algorithm under both IAE and ISE objective functions. This result clearly illustrates that the proposed TEO algorithm with the ISE-based tuning presents high performances compared to the IAE criterion case. The settling time is improved in the case of ISE-based TEO method at the expense of a slight increase in the overshoot. Figure $4 \mathrm{~b}$ presents the same comparison but for the DC-link voltage loop. The TEO-based controller with the ISE optimization criterion leads to better results compared to those with the IAE index. 
Table 1. Statistical outputs of optimization problem (8) over 10 executions

\begin{tabular}{ccccccc}
\hline Index & Statical result & PSO & HSA & GA & WCA & TEO \\
\hline \multirow{4}{*}{ IAE } & Worst & 0.8048 & 0.8048 & 0.8041 & 0.7822 & 0.6999 \\
& Mean & 0.8039 & 0.8004 & 0.7911 & 0.7816 & 0.6403 \\
& Best & 0.8031 & 0.7885 & 0.7813 & 0.7811 & 0.6007 \\
& STD & $6.3 \mathrm{e}-4$ & $4.8 \mathrm{e}-3$ & $8.7 \mathrm{e}-3$ & $4.19 \mathrm{e}-4$ & $4.03 \mathrm{e}-3$ \\
& ET (sec) & 14150 & 55851 & 140807 & 94895 & 88920 \\
& Worst & 0.4980 & 0.4971 & 0.4884 & 0.4966 & 0.4570 \\
ISE & Mean & 0.4969 & 0.4959 & 0.4871 & 0.4958 & 0.4563 \\
& Best & 0.4958 & 0.4952 & 0.4852 & 0.4952 & 0.4558 \\
& STD & $7.7 \mathrm{e}-4$ & $6.5 \mathrm{e}-4$ & $1.1 \mathrm{e}-3$ & $5.2 \mathrm{e}-4$ & $4.8 \mathrm{e}-4$ \\
& ET (sec) & 12867 & 26458 & 136559 & 83564 & 68951 \\
\hline
\end{tabular}

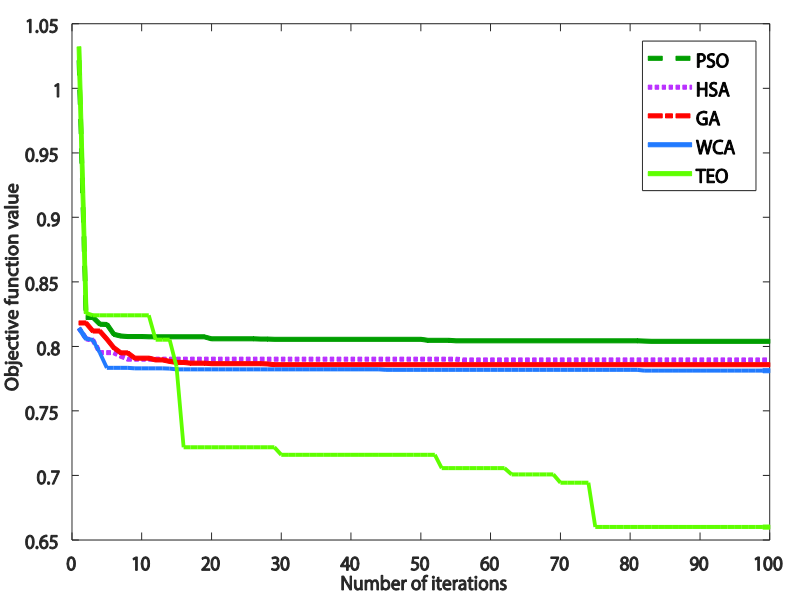

(a)

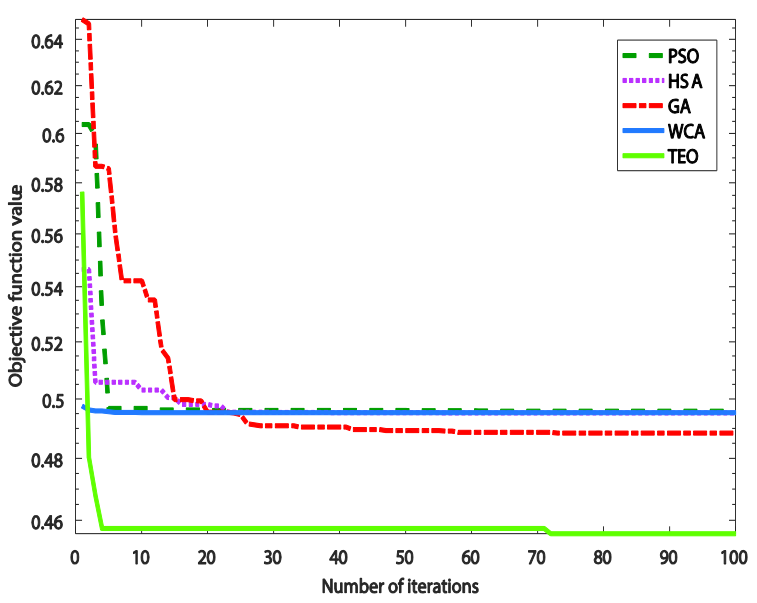

(b)

Figure 1. Convergence rate comparison of the proposed algorithms :(a) IAE criterion; (b) ISE criterion

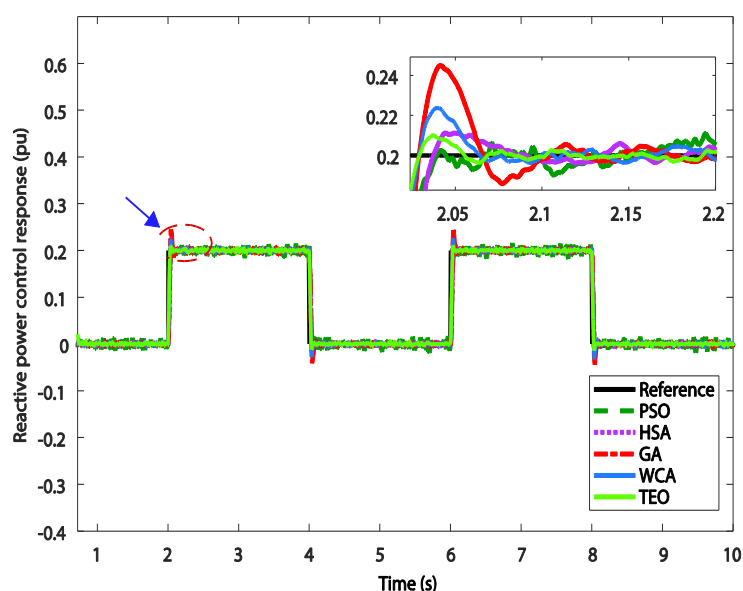

(a)

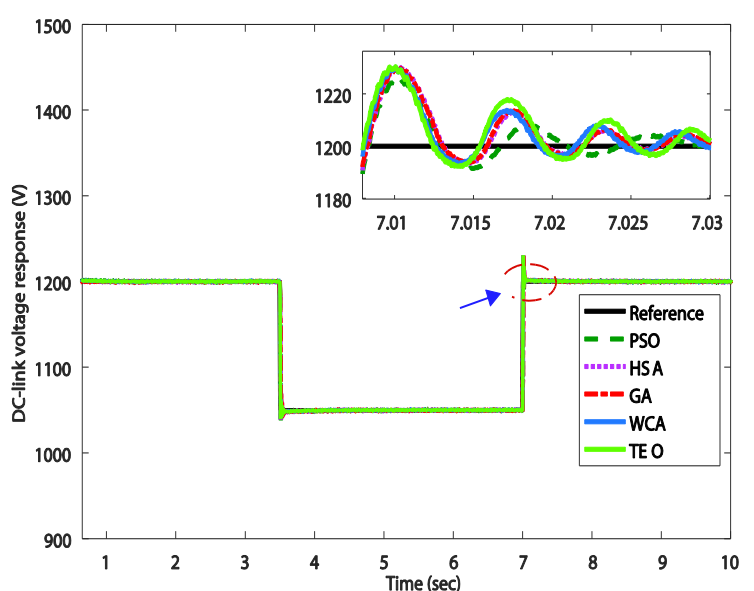

(b)

Figure 2. TEO-tuned PI controlled based ISE index under different step changes: (a) reactive power dynamics, (b) DC-link voltage dynamics

Figure 1 Convergence rate comparison of the proposed algorithms: (a) IAE criterion, (b) ISE criterion. Figure 2 TEO-tuned PI controlled based ISE index under different step changes: (a) reactive power dynamics, (b) DC-link voltage dynamics. 


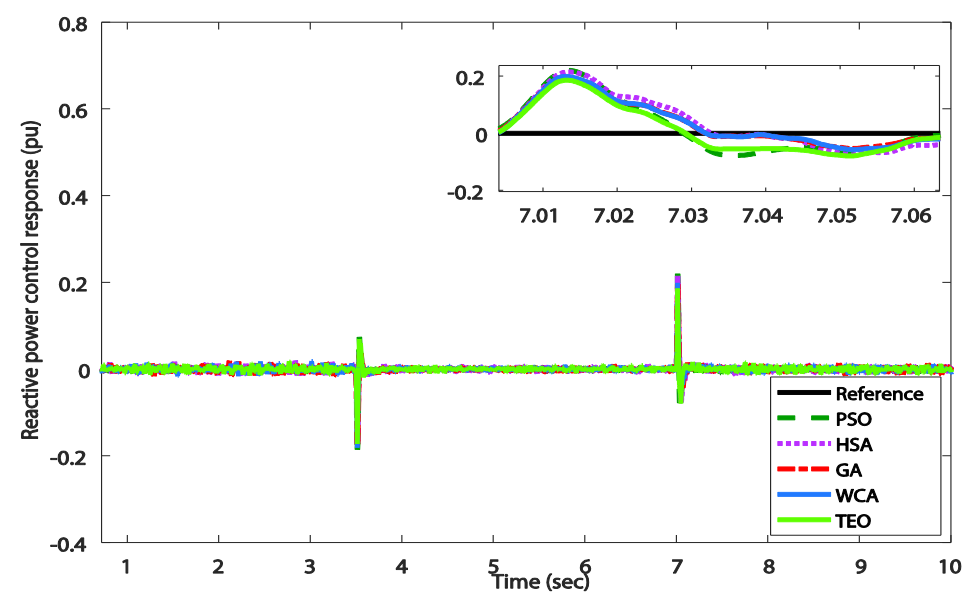

Figure 3. TEO-tuned PI controlled reactive power dynamics under a drop of grid voltage: ISE index

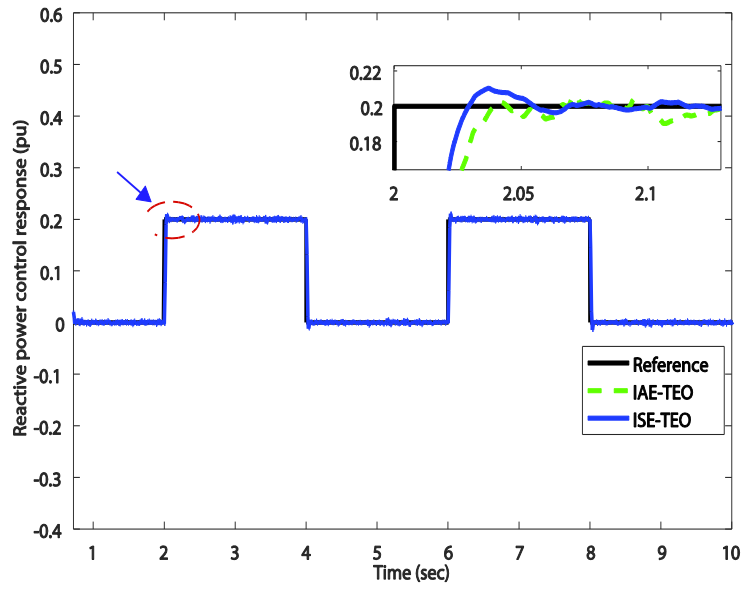

(a)

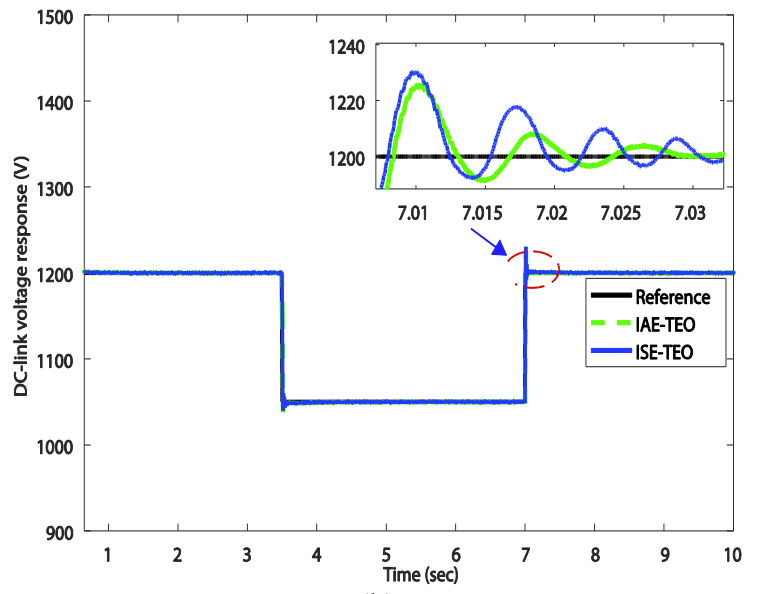

(b)

Figure 4. Performance comparison of IAE- and ISE-based PI controllers tuning :(a) reactive power dynamics, (b) DC-link voltage dynamics

\subsection{Sensitivity analysis}

In the TEO formalism, $c_{1}$ and $c_{2}$ parameters are presented to decrease the randomness of the TEO method with the increase of iterations leading to increase the exploration performance. The capacity of $T M$ is defined as a predefined input, which can reinforce the effectivenesses of the method without enhancing the elapsed time $[15,20]$. To this end, the optimization problem (8) using the IAE index is investigated by altering the main control inputs of the TEO algorithm. From Table 2 in scenario A, the case with $c_{1}=1, c_{2}=1$ displays the superiority of the TEO algorithm compared to the other parameter sets in the same scenario. Moreover, it can be noted from scenario B that the defined input $T M=12$ results to the best solution. Lastly, scenario $\mathrm{C}$ tests the influence of the pro input on the TEO method efficiency.

\subsection{Comparison of classical PI and TEO-tuned PI controllers}

A comparison of the introduced TEO algorithm with the common Ziegler-Nichols and Tyreus-Luyben approaches is performed for the PI controllers' design [21, 22]. Figure 5 shows the timedomain variations of the reactive power according to the proposed tuning methods. Referring to this result, TEO-adjusted PI regulators with the IAE and ISE criteria indicate better performance in comparison with the Ziegler-Nichols and Tyreus-Luyben based approaches in terms of settling time, overshoot and steady-state error indices. 


\subsection{Statistical analysis and comparison}

A statistical comparison has executed to indicate the significance of the TEO-based adjusting strategy over other ones. Friedman's test provides the F-score of 7.07 [23]. The F-statistics at a confidence level of $90 \%$ is 4.11 [24]. Since the F-statistics value is smaller than the computed F-score, the null hypothesis can be rejected and it can be concluded that the performance of the algorithms is statistically different. Bonferroni-Dunn test is performed to check whether the introduced TEO method is significantly better than another algorithm [25]. The identical critical differences of the adopted algorithms at the confidence level $\alpha=0.05$ and $\alpha=0.1$ are computed as $\mathrm{CD}_{0.05}=3,11$ and $\mathrm{CD}_{0.1}=2,60$, respectively. This indicates that the TEO method executes at least clearly better than the PSO one over the solutions equality.

Table 2. Comparison against various values of $c_{1}$ and $c_{2}$

\begin{tabular}{ccccc}
\hline Scenario A & Worst & Mean & Best & STD \\
& \multicolumn{2}{c}{$T M=12$, pro $=0.5$ and $k_{\max }=100$} \\
\hline$c_{1}=0, c_{2}=0$ & 0.7695 & 0.7520 & 0.73845 & $1.10 \mathrm{E}-3$ \\
$c_{1}=1, c_{2}=0$ & 0.7645 & 0.7408 & 0.7225 & $1.40 \mathrm{E}-3$ \\
$c_{1}=0, c_{2}=1$ & 0.7546 & 0.7404 & 0.7312 & $8.23 \mathrm{E}-4$ \\
$c_{1}=1, c_{2}=1$ & 0.6999 & 0.6403 & $\mathbf{0 . 6 0 0 7}$ & $4.03 \mathrm{E}-3$ \\
Scenario B & $c_{1}=1, c_{2}=1$, pro $=0.5$ and $k_{\max }=100$ \\
$T M=4$ & 0.7992 & 0.7947 & 0.7895 & $3.51 \mathrm{E}-4$ \\
$T M=8$ & 0.7546 & 0.7407 & 0.7312 & $8.49 \mathrm{E}-4$ \\
$T M=12$ & 0.6999 & 0.6403 & $\mathbf{0 . 6 0 0 7}$ & $4.03 \mathrm{E}-3$ \\
Scenario C & $c_{1}=1, c_{2}=1, T M=12$ and $k_{\max }=100$ \\
pro $=0.20$ & 0.7963 & 0.7945 & 0.7933 & $1.06 \mathrm{E}-3$ \\
pro $=0.35$ & 0.7948 & 0.7934 & 0.7915 & $1.14 \mathrm{E}-3$ \\
pro $=0.50$ & 0.6999 & 0.6403 & $\mathbf{0 . 6 0 0 7}$ & $4.03 \mathrm{E}-3$ \\
\hline
\end{tabular}

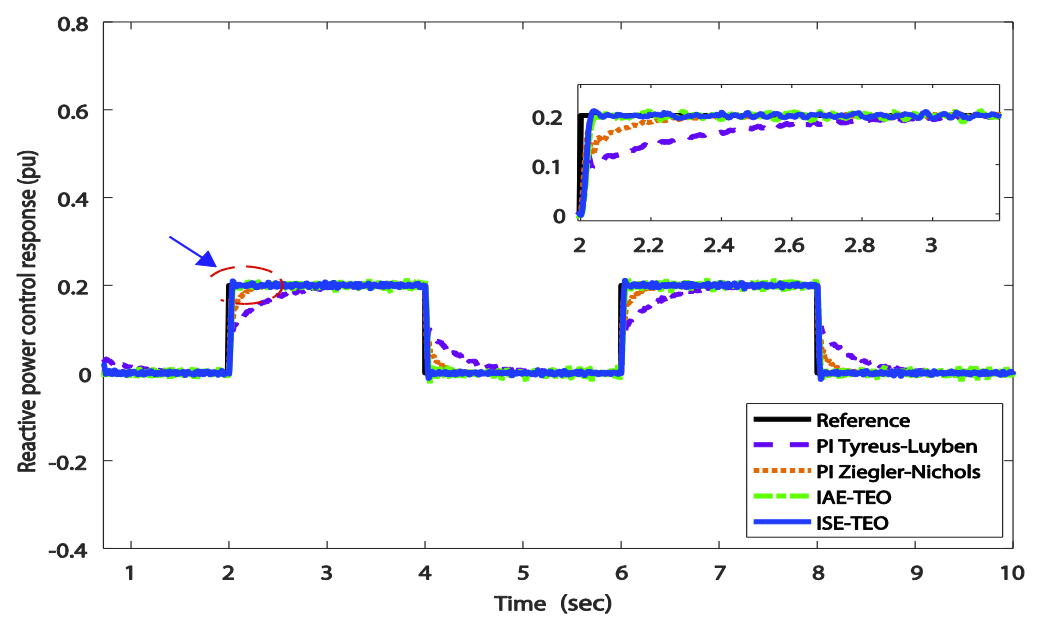

Figure 5. Performance comparison of the regulated reactive power against various PI adjusting strategies

\section{CONCLUSION}

This paper has presented a new TEO metaheuristic method for optimal PI controllers' parameters tuning of a DFIG-based wind conversion system. In this work, only external PI loops in the RSC and GSC parts are discussed. The tuning of these PI controllers' gains is investigated as an optimization problem against nonlinear and non-smooth operational limitations. The exploration and exploitation mechanisms of the TEO method make it more suitable to resolve such a formulated control issue. A comparison study between the TEO technique and classical meta-heuristics algorithms was achieved. The demonstrative results conducted that the used TEO algorithm outperforms all other proposed metaheuristics in terms of global search abilities, robustness and fast convergence. Moreover, the analysis study of the TEO algorithm revealed that this PI controllers' tuning method is a competitive one with good performance compared to 
the well-known Ziegler-Nichols and Tyreus-Luyben adjusting approaches. The obtained results indicate that the introduced TEO-based strategy is a favourable method for regulating the wind energy conversion systems by tuning the unknown PI controllers' gains.

\section{REFERENCES}

[1] J. D. Pitteloud, World Wind Energy Association, [Online]. Available at: https://library.wwindea.org/globalstatistics-2018-preliminary/ (Accessed: June 2019).

[2] J. Hu, et al., "Dynamic Modeling and Improved Control of DFIG Under Distorted Grid Voltage Conditions," in IEEE Transactions on Energy Conversion, vol. 26, no. 1, pp. 163-175, March 2011. doi: 10.1109/TEC.2010.2071875.

[3] M. M. Alhato, and S. Bouallègue, "Direct Power Control Optimization for Doubly Fed Induction Generator Based Wind Turbine Systems," Math. Comput. Appl, vol. 24, no. 77, pp. 1-28, 2019.

[4] H. Hachemi, A. Allali, and B. Belkacem, "Control of the Powerquality for a DFIG Powered by Multilevel Inverters," Int. J. Electr. Comput. Eng, vol. 10, no. 5, pp. 4592-4603, Oct 2020.

[5] M. Mohseni, S. M. Islam, and M. A. S. Masoumm, "Enhanced Hysteresis-based Current Regulators in Vector Control of DFIG Wind Turbines," IEEE Trans. Power Electron, vol. 26, no. 1, pp. 223-234, Jan 2011.

[6] M. M. ALhato, and S. Bouallègue, "Whale Optimization Algorithm for Active Damping of LCL-Filter-based GridConnected Converters," Int. J. Energ. Res, vol. 9, no. 2, pp. 986-996, June 2019.

[7] K. Khoud, S. Bouallègue, and M. Ayadi, "Design and co-simulation of a fuzzy gain-scheduled PID controller based on particle swarm optimization algorithms for a quad tilt wing unmanned aerial vehicle," T. I. Meas. Control, vol. 40, no. 14, Jan 2018.

[8] J. Kennedy and R. Eberhart, "Particle swarm optimization," Proceedings of ICNN'95-International Conference on Neural Networks, Perth, WA, Australia, vol. 4, pp. 1942-1948, 1995. doi: 10.1109/ICNN.1995.488968.

[9] E. Rashedi, H. Pour, and S. Saryazdi, "GSA: A Gravitational Search Algorithm," Inf. Sci, vol. 179, no. 13, pp. 2232-2248.

[10] S. Albatran, M. Alomoush, and A. Koran, "Gravitational-Search Algorithm for Optimal Controllers Design of Doubly-fed Induction Generator," Int. J. Electr. Comput. Eng, vol. 81, no. 2, pp. 780-792, Apr 2018.

[11] T. T. Hoang, and T. H. Le, "Application of Mutant Particle Swarm Optimization for MPPT in Photovoltaic System," Indones. J. Electrical Eng. Comput. Sci, vol. 19, no. 2, pp. 600-607, Aug 2020.

[12] J. P. A. Vieira, M. N. A. Nunes and U. H. Bezerra, "Design of optimal PI controllers for doubly fed induction generators in wind turbines using genetic algorithm," 2008 IEEE Power and Energy Society General MeetingConversion and Delivery of Electrical Energy in the 21st Century, Pittsburgh, PA, pp. 1-7, 2008.

[13] Y. Bekakra, and D. B. Attous, "Optimal Tuning of PI controller Using PSO Optimization for Indirect Power Control for DFIG based Wind Turbine with MPPT," Int. J. Sys. Assur. Eng. Manag, vol. 5, no. 3, pp. 219-229, Sep 2014.

[14] S. Mirjalili, and A. Lewis, "The Whale Optimization Algorithm," Adv. Eng. Softw, vol. 95, pp. 51-67, May 2016.

[15] A. Kaveh, and A. Dadras, "A Novel Meta-Heuristic Optimization Algorithm: Thermal Exchange Optimization," Adv. Eng. Softw, vol. 110, pp. 69-84, Aug 2017.

[16] D. Xu, et al., "Advanced Control of Doubly Fed Induction Generator for Wind Power Systems," 1st ed. Hoboken, New Jersey: John Wiley \& Sons, Inc, 2018.

[17] S. Gagrai, S. Mishra, and M. Singh, "Performance Analysis of Grid Integrated Doubly Fed Induction Generator for a Small Hydropower Plant," Int. J. Energ. Res, vol. 8, no 4, pp. 2310-2323, Dec 2018.

[18] Hato, M. M., Bouallègue S., and Ayadi M., "Water Cycle Algorithm-Tuned PI Control of a Doubly Fed Induction Generator for Wind Energy Conversion," In 9th Int. Renew. Energy Congress, Tunisia, pp. 1-6, 2018.

[19] W. Qiao, "Dynamic modeling and control of doubly fed induction generators driven by wind turbines," 2009 IEEE/PES Power Systems Conference and Exposition, Seattle, WA, pp. 1-8, 2009. doi: 10.1109/PSCE.2009.4840245.

[20] A. Kaveh, and M. I. Ghazaan, "Enhanced Colliding Bodies Optimization for Design Problems with Continuous and Discrete Variables," Adv. Eng. Softw, vol. 77, pp. 66-75, Nov 2014.

[21] K. S. Chia, "Ziegler-Nichols Based Proportional-Integral-Derivative Controller for a Line Tracking Robot," Indones. J. Electrical Eng. Comput. Sci, vol. 9, no. 1, pp. 221-226, Jan 2018.

[22] S. Deepa, N. Anipriya, and R. Subbulakshmy, "Design of Controllers for Continuous Stirred Tank Reactor," Int. J. Power Electron. Drive Syst, vol. 5, no. 4, pp. 576-582, Feb 2015.

[23] A. K. Sadhu, et al., "Synergism of Firefly Algorithm and Q-learning for Robot Arm Path Planning," Swarm. Evol. Comput, vol. 43, pp. 50-68, Dec 2018.

[24] J. H. Zar, "Biostatistical Analysis," 5th ed. New Jersey: Prentice Hall, 2010.

[25] B. S. Raghuwanshi, and S. Shukla, "Generalized Class-Specific Kernelized Extreme Learning Machine for Multiclass Imbalanced Learning," Expert. Syst. Appl, vol. 121, pp. 244-255, May 2019. 